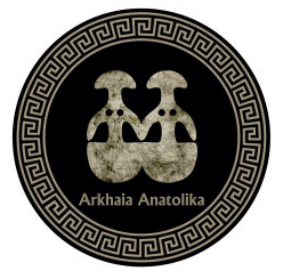

Arkhaia Anatolika

Anadolu Arkeolojisi Araştırmaları Dergisi

The Journal of Anatolian Archaeological Studies

Volume 3 (2020)

\title{
Akkise/Yahyalı Höyük: Suğla Gölü Kenarında Yeni Bir Prehistorik Yerleşim
}

\author{
Akkise/Nahyalı Hoyuk: A New Prehistoric Settlement by Lake Suğla
}

\section{Ramazan GÜNDÜZ}

ORCID: 0000-0003-4113-119X

Geliş Tarihi: 10.11.2020 | Kabul Tarihi: 24.11.2020 | Online Yayın Tarihi: 02.12.2020

Makale Künyesi: R. Gündüz, “Akkise/Yahyalı Höyük: Suğla Gölü Kenarında Yeni Bir Prehistorik Yerleşim", Arkhaia Anatolika 3 (2020), 244-253. DOI: 10.32949/Arkhaia.2020.22
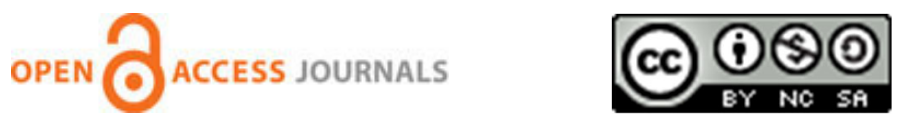

Arkhaia Anatolika, Anadolu Arkeolojisi Araştırmaları Dergisi "Açık Erişimli" (Open Access) bir dergidir. Kullanıcılar, dergide yayınlanan makalelerin tamamın tam metin olarak okuyabilir, indirebilir, makalelerin çıktısını alabilir ve kaynak göstermek suretiyle bilimsel çalışmalarında bu makalelerden faydalanabilir. Bunun için yayıncıdan ve yazar(lar)dan izin almasına gerek yoktur.

Dergide yayınlanan makalelerin bilimsel ve hukuki sorumluluğu tamamen yazar(lar)ına aittir.

Arkhaia Anatolika, The Journal of Anatolian Archaeological Studies follows Open Access as a publishing model. This model provides immediate, worldwide, barrier-free access to the full text of research articles without requiring a subscription to the articles published in this journal. Published material is freely available to all interested online readers.

The scientific and legal propriety of the articles published in the journal belongs exclusively to the author(s). 


\title{
Akkise/Yahyalı Höyük: Suğla Gölü Kenarında Yeni Bir Prehistorik Yerleşim
}

\author{
Akkise/Nahyalı Hoyuk: A New Prehistoric Settlement by Lake Suğla
}

\section{Ramazan GÜNDÜZ*}

\begin{abstract}
$\ddot{O} z$
Bu çalışma, “2020 yılı Suğla Gölü Çevresi Prehistorik Dönem Yüzey Araştırması” nda tespit edilen yeni bir höyük yerleşimine ait buluntuların ön değerlendirmesidir. Akkise/Yahyalı Höyük yerleşim yeri Suğla Gölü'nün yaklaşık 1 km güneydoğusunda bulunan Konya iline bağlı Ahırlı ilçesinin, Akkise mahallesi sınırları içerisinde yer almaktadır. Orta Anadolu'nun güneyinde, Göller Bölgesi ile Konya Ovası arasında kalan ve Beyşehir-Suğla Oluğu olarak adlandırılan bu bölgede 1960'lı yıllarda yapılan ilk çalışmalarda bölgenin Prehistorik dönemleri hakkında ilk bilgiler elde edilmiştir. Bu dönemde Suberde, Erbaba Höyük gibi yerleşmelerde yapılan kazılarda söz konusu yerleşmelerin Neolitik Dönem'de göl kenarlarına kurulduğuna dair önemli bulgular tespit edilmiştir. Daha sonra Suğla Gölü'ne yakın bir noktada 2002 yılında DSİ sulama kanalı açma çalışmaları yapılmıştır. Bu kanal kazısında Gökhöyük Bağları Höyük olarak adlandırılan alanda arkeolojik eserlerin ortaya çıkmasıyla Konya Müze Müdürlüğü'nce kurtarma kazıları yapılmıştır. Açı̆̆a çıkarılan yerleşmede bölgenin Prehistorik dönemleri hakkında önemli bilgiler elde edilmiştir. 2020 yılında “Suğla Gölü Çevresi Prehistorik Dönem Yüzey Araştırması" kapsamında tespit edilen Akkise/Yahyalı Höyük buluntuları bölgede yeni bir Prehistorik Dönem yerleşmesinin varlığına dair ilk bulguları ortaya koymuştur. Bölgenin Neolitik Dönem'e tarihlenen Erbaba Höyük, Suberde Höyük ve Gökhöyük Bağları Höyük gibi yerleşmelerinde açığa çıkarılan buluntulardan Neolitik Dönem alet endüstrisi ve çanak-çömlek yapım teknikleri hakkında önemli bilgiler elde edilmiştir. Bu yerleşmelerde Neolitik Dönem'e tarihlenen tabakalarda bulunan obsidyen ve çakmak taşı aletler yanında öğütme taşları ile pişmiş toprak eserlerin benzerleri Akkise/Yahyalı Höyük'te yüzeyde tespit edilmiştir. Yerleşmede yüzeyden toplanan eserlerden bu yerleşim yerinin Geç Neolitik, Erken Kalkolitik Dönem'e tarihlenebileceği düşünülmektedir. Bu bağlamda ileride Akkise/Yahyalı Höyük'te yapılacak arkeolojik kazıların Beyşehir-Suğla Oluğu olarak da adlandırılan havzanın Neolitikleşme sürecine dair önemli bilgiler vereceği tahmin edilmektedir.
\end{abstract}

Anahtar Kelimeler: Neolitik, Prehistorya, Konya, Akkise, Suğla Gölü

\section{Abstract}

This study reveals a preliminary evaluation of the findings obtained from a new settlement detected during the Survey of Prehistoric Period of the Suğla Lake Vicinity in 2020. The settlement of Akkise/Yahyalı Höyük is located within the borders of Akkise District in Konya province, approximately $1 \mathrm{~km}$ the northeast of

\footnotetext{
* Arş. Gör. Dr. Ramazan Gündüz, Selçuk Üniversitesi, Edebiyat Fakültesi, Arkeoloji Bölümü, Konya/TÜRKIYYE. E-mail: ramazangunduz@selcuk.edu.tr / Orcid No: 0000-0003-4113-119X
}

Söz konusu çalışma T.C. Kültür ve Turizm Bakanlığı'nın izni ile Dr. Ramazan Gündüz'ün başkanlığındaki Suğla Gölü Çevresi Prehistorik Dönem Yüzey Araştırması YA014208(2020) proje numaralı çalışma ile Selçuk Üniversitesi, Bilimsel Araştırma Projeleri Koordinatörlüğü tarafından desteklenen 20401138 numaralı "Seydişehir İlçesi Prehistorik Dönem Yüzey Araştırması" adlı proje kapsamında hazırlanmıştır. Vermiş oldukları izin için T.C. Kültür ve Turizm Bakanlığı'na, maddi desteklerinden dolayı da S.Ü. Bilimsel Araştırma Projeleri Koordinatörlüğü'ne teşekkürlerimizi sunarız. Ayrıca Suğla Gölü Çevresi Prehistorik Dönem Yüzey Araştırması Projesine maddi, manevi desteğini esirgemeyen Seydişehir Belediye Başkanlığı'na ve Seydişehir Kaymakamlığı'na teşekkür ederiz. 
Lake Suğla. The first data about the prehistoric periods of the region were obtained from the studies conducted in the 1960s in this region, which is located between the Lakes Region and Konya Plain in the South of Central Anatolia that is called the Beyşehir-Suğla Trough. During this period, excavations in settlements such as Suberde and Erbaba Höyük revealed important findings suggesting that these settlements be established on the lakeside in the Neolithic Period. Then, in 2002, DSI works to build irrigation canal were carried out at a location close to Suğla Lake. With the unearth of archaeological artifacts in the area called Gökhöyük Bağları Höyük during the digging out for the canal, rescue excavations were carried out by the Konya Museum Directorate. In the unearthed settlement, important data about the prehistoric periods of the region were gathered. The Akkise/Yahyalı Höyük finds, which were discovered during the Survey of Prehistoric Period of the Suğla Lake Vicinity in 2020, revealed the existence of a totally new prehistoric settlement in the region. From the finds unearthed in settlements such as Erbaba Höyük, Suberde Höyük and Gökhöyük Bağları Höyük, dating the Neolithic Period, important information about the Neolithic Period tool industry and pottery making techniques was obtained. In these settlements, the obsidian and flintstone tools found in the layers dated back the Neolithic period, as well as the similar grinding stones and terracotta artifacts were found on the surface in Akkise/Yahyalı Hoyük. Among From the artifacts collected from the surface of the settlement, it is thought that this settlement can be dated to the Late Neolithic, Early Chalcolithic Period.

In this context, it is estimated that the archaeological excavations to be carried out in Akkise/Yahyalı Höyük in the future will provide important information about the Neolithization process of the Basin, also known as the Beyşehir-Suğla Trough.

Keywords: Neolithic, Prehistory, Konya, Akkise, Lake Suğla

\section{Giriş}

Akkise/Yahyalı Höyük yerleşim yeri Suğla Gölü'nün yaklaşık $1 \mathrm{~km}$ güneydoğusunda, Konya iline bağlı olan Ahırlı ilçesi, Akkise kasabası/mahallesi sınırları içerisinde bulunmaktadır (fig. 1) ${ }^{1}$. Akkise/Yahyalı Höyük yerleşim yeri 37.359057 enlem ve 32.106283 boylam koordinatlarında, deniz seviyesinden yaklaşık $1191 \mathrm{~m}$ yüksekliktedir. Göller Bölgesi ile İç Anadolu'nun en güneyinde, Beyşehir-Suğla Oluğu olarak adlandırılan koridorun Konya'ya bakan kısmında bulunur. Suğla Gölü'nün kuzey batısında bulunan Suberde Höyük ${ }^{2}$ ve kuzey doğusunda yer alan Gökhöyük Bağları Höyük ${ }^{3}$ Prehistorik Dönem yerleşim yerlerine yaklaşı $12 \mathrm{~km}$ mesafededir.

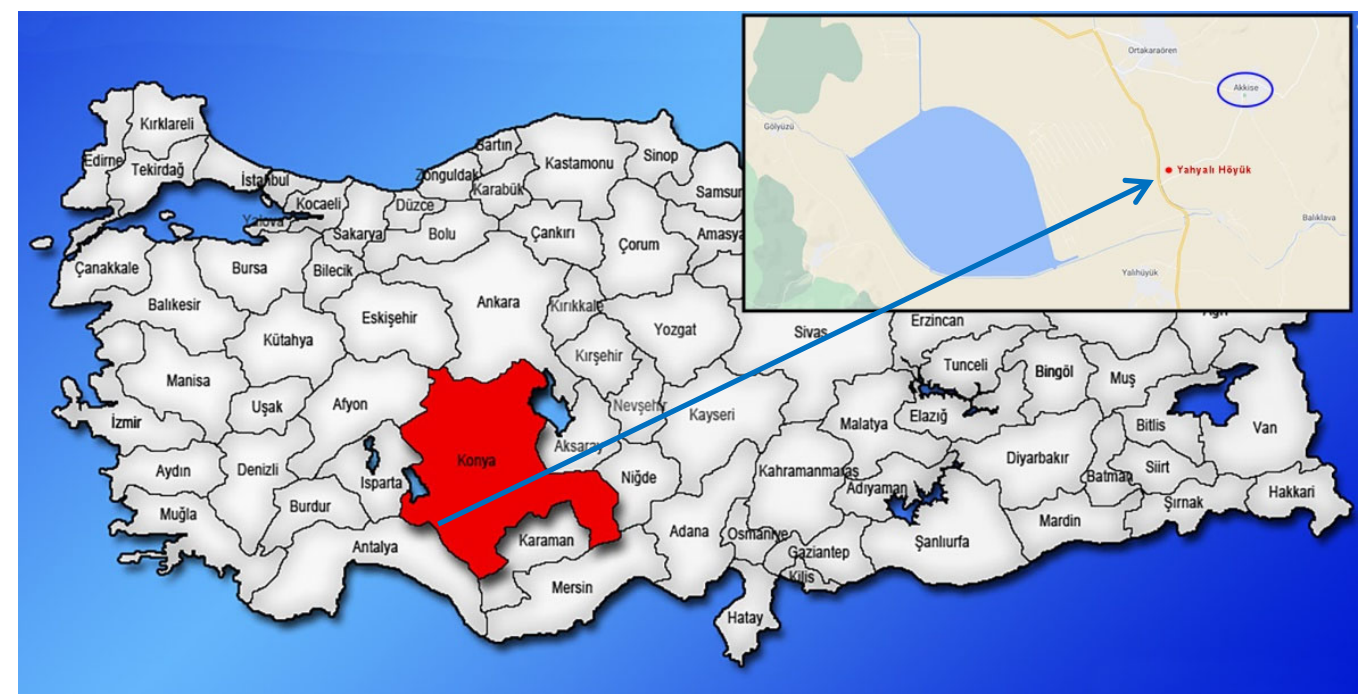

Figür 1: Akkise/Yahyalı Höyük'ün konumu

\footnotetext{
1 Yerleşim yeri “2020 yılı Suğla Gölü Çevresi Prehistorik Dönem Yüzey Araştırması” kapsamında Suğla Gölü çevresinde çalışmalar yapan Selçuk Üniversitesi, Arkeoloji Bölümü Öğretim Elemanı Dr. Ramazan Gündüz başkanlığındaki ekip tarafından tespit edilmiştir.

2 Suberde' nin ilk sakinlerinin seramiksiz Neolitik Dönem'de buraya yerleşen avcı-toplayıcı bir grup olduğu ileri sürülmektedir (Bordaz 1969, 58-59).

3 Gökhöyük Bağları Höyük'te yapılan kurtarma kazılarından elde edilen sonuçlara göre yerleşme seramikli Neolitik Dönem'e tarihlenmektedir (Gündüz 2019, 43).
} 
Yerleşme bulunduğu konum itibari ile güney yönünde Suğla Gölü'ne bakan bir yamaçta kurulmuştur. Olasılıkla Prehistorik dönemlerde Suğla Gölü' nün bir kıyı yerleşmesi durumundadır. Yerleşmenin batısı güney-kuzey yönünde Suğla Gölü'nün çekilmesiyle oluşan düzlükler ile çevriliyken, doğuya doğru yükselti artmaktadır. Konya Ovası'ndan daha büyük bir yükseltiye sahip olan bölgede bu yükselti Toroslara yaklaştıkça kademeli olarak artar. Konya Ovası'na oranla daha fazla yağışlı olan bölgede kışları yoğun kar yağışı ve sert geçmektedir. Buna bağlı olarak da bu coğrafya Çarşamba Çayı gibi kışları aldığı yağışa bağlı olarak taşıdığı su miktarı değişen kaynaklara sahiptir. Bu coğrafya içinde bulunan göllerden hem Suğla Gölü'nün hem de Beyşehir Gölü'nün yazları kurak geçmesinden etkilendiği, kışları ise artan yağışlarla su seviyelerinin değişkenlik gösterdiği bildirilmektedir ${ }^{4}$. Bu mevsimsel su seviyesi değişikliklerinin Prehistorik dönemlerde de olduğuna dair veriler ise Suberde'den gelmektedir5. Bölgede ilk arkeolojik yüzey araştırmaları 1950'li yıllarda J. Mellaart ${ }^{6}$ tarafından, daha sonra 1960'lı yılarda J. Bordaz ${ }^{7}$ tarafından yapılmıştır. H. Bahar tarafından 2006 yılında gezilen bölgenin Hellenistik ve Roma dönemleri 2006-2019 yılları arasında A. Baldıran tarafından araştırılmıştır.

Akkise/Yahyalı yerleşim yeri, “2020 yılı Suğla Gölü Çevresi Prehistorik Dönem Yüzey Araştırması" kapsamında Akkise'nin göle bakan yamaçlarının incelenmesi sırasında keşfedilmiştir. Alandan yoğun çanak-çömlek parçaları ile birlikte obsidyen ve çakmaktaşından alet ve yonga parçaları toplanmıştır. Bunlara ilaveten yüzeyde çok sayıda ögütme taşı ile birlikte havaneli de tespit edilmiştir. Ayrıca yerleşim yerinde defineciler tarafından açılan kaçak kazı çukurunun oluşturduğu tahribat ile taş temelli mimari yapı kalıntısının da açığa çıktığı görülmüştür. Burada ele geçen buluntulardan edinilen ilk izlenimler, Akkise/Yahyalı Höyük'ün Prehistorik dönemlerde yerleşim gördüğü yönündedir.

\section{Mimari Kalıntılar}

Akkise/Yahyalı Höyük'ün mimari geleneklerine dair ipuçları defineciler tarafından açılan kaçak kazı çukurunda incelenen kesit üzerinden gelmektedir. Çukur içinde yaklaşık 1 $\mathrm{m}$ yüksekliğinde, $2 \mathrm{~m}$ uzunluğunda, taş duvarı görülen bir mimari yapının kalıntısı açığa çıkarılmıştır. Bu mimari yapının dolgusu içinde ve çukurdan dışarı atılan toprak yüzeyinde yoğun şekilde bulunan pişmiş toprak seramik ve obsidyen parçalarından, burada Prehistorik Dönem'e tarihlenebilecek, taş temelli duvarlara sahip, dikdörtgen veya kare planlı bir mimari geleneğin var olduğu anlaşılmaktadır (fig. 2). Bölgede bulunabilecek bazalt taşından örülmüş olan duvar, yaklaşık 10-15 cm genişliğinde, $30 \mathrm{~cm}$ uzunluğundaki düzgün taşlardan oluşmaktadır. Taş temelde birleştirici malzeme olarak çamur harç kullanılmıştır. Defineciler tarafından duvardan sökülerek çukurun kenarına atılan toprak içinde bulunan küçük sıva parçaları ve taşlar üzerinde bulunan sıva izlerinden yapının sıvalı olabileceği akla gelmektedir.

Orta Anadolu'nun güneyinde, Konya Ovası sınırları içerisinde bulunan ve Neolitik Dönem'e tarihlenen Çatalhöyük ${ }^{8}$ ile Can Hasan ${ }^{9}$ yerleşmelerinde açığa çıkarılan mimari

\footnotetext{
4 Kuzucuoğlu 2002, 39-40.

${ }^{5}$ J. Bordaz, Suğla Gölü'nün yılın farklı zamanlarında sularının artarak taşması sonucunda Suberde' nin adaya dönüştüğünü belirtmektedir (Bordaz 1969, 44).

${ }^{6}$ Mellaart 1954, 175-240; Mellaart 1958, 311-353.

7 Bordaz 1969, 43.

8 J. Mellaart, Çatalhöyük kazılarında açığa çıkarılan mimari yapıların tamamında kerpiç kullanıldığını bildirmektedir (Mellaart 1967, 55).

9 D. French, Can Hasan yerleşmesinde Neolitik Dönem boyunca duvarlar ve kapılarda taş kullanımının çok nadir görüldüğünü bildirmektedir. Can Hasan yerleşmesinde mimari yapı elamanı olarak yaygın kullanılan malzeme kerpiçtir (French 1998, 20).
} 
yapılarda temel seviyesinde taş kullanıldığına dair bir bulgu yoktur. Bu yerleşmelerdeki mimari yapılar kerpiç temelli ve/veya kerpiçlerle örülen duvarlara sahiptir. Suğla Havzası içinde bulunan Suberde Höyük'te de kerpiç temelli yapılar vardır. Bunlardan yalnız Gökhöyük Bağları Höyük'te Neolitik Dönem'e tarihlenen yapılardan bazılarının temel seviyesinde taş kullanıldığı kazı raporlarından bilinmektedir ${ }^{10}$. Bu bağlamda Akkise/Yahyalı Höyük yerleşmesinde ileride yapılacak kazılarda açı̆̆a çıkarılacak mimari yapılar, Suğla Gölü Havzası'nın Prehistorik Dönem mimari geleneklerinin daha iyi anlaşılmasına katkı sağlayacaktır.

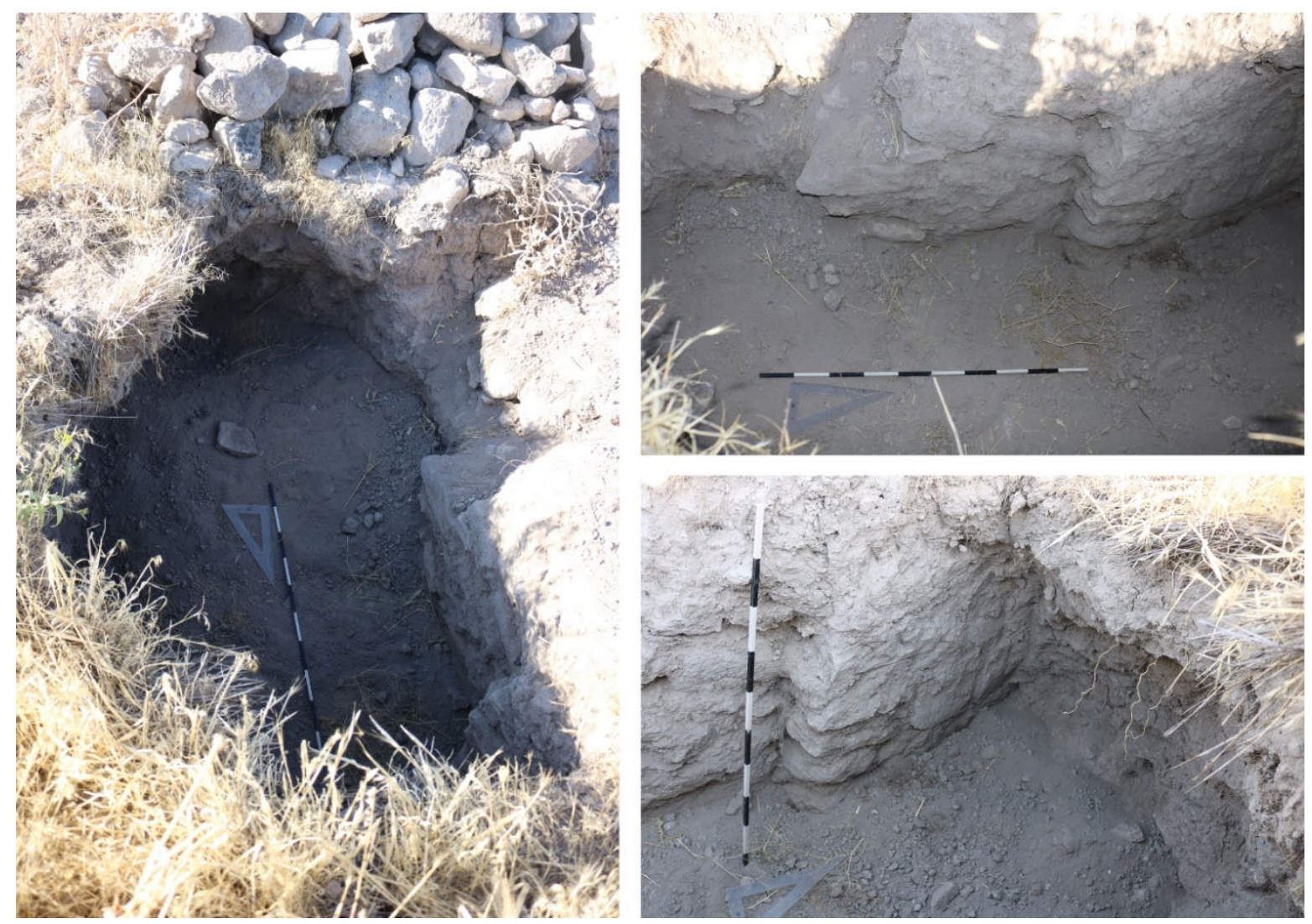

Figür 2: Akkise/Yahyalı Höyük'te definecilerin kaçak kazıları sonrasında açı̆̆a çıkan taş duvarlı mimari yapı parçası

\section{Yontma Taş Aletler}

\section{Obsidyen}

Akkise/Yahyalı Höyük'te yapılan belgeleme ve tescilleme çalışmaları esnasında toplam 22 parçadan oluşan yontma taş alet ve alet parçaları bulunmuştur ${ }^{11}$. Tespit edilen bu buluntu topluluğu 11 adet obsidyen ve 11 adet çakmak taşından oluşmaktadır. K. Demir'in verdiği bilgiye göre, obsidyenlerden bir tanesi konik dilgi çekirdeği parçası (fig. 3d), 4 tanesi dilgi bölümü (fig. 3e-h), 1 tanesi iki yüzeyli düzeltilenmiş uç (fig. 3j), 5 tanesi ise yongalama artığından oluşmaktadır (fig. 3). Makroskopik gözlemlere göre siyah renkte olan obsidyen parçalarının Orta Anadolu kökenli oldukları düşünülmektedir. Bununla birlikte ele geçen

10 Konya Müze Müdürlüğü'nce 2002-2005 yılları arasında kurtarma kazıları yapılan Gökhöyük Bağları Höyük'ü kazı raporlarının ayrıntılı olarak verildiği tez çalışmasında Enver Akgün Neolitik Dönem'e tarihlenen yapıların bir kısmının taş temel üzeri kerpiç duvarları olduğunu belirtmektedir (Akgün 2019, 101).

11 Suğla Gölü Çevresi Prehistorik Dönem Yüzey Araştırmaları'nda ele geçen Yontma Taş buluntularının ayrıntılı bilimsel çalışmaları daha sonra Denizli Pamukkale Üniversitesi, Fen Edebiyat Fakültesi, Arkeoloji Bölümü, Prehistorya Anabilim Dalı Öğretim Görevlisi Kerem Demir tarafından bilim dünyasıyla paylaşılacaktır. Yüzey araştırması heyet üyemiz olan Sayın Demir'e aletlerin tipolojileri konusunda verdiği bilgi ve makalede kullanılan Yahyalı Höyük yontma taş alet parçalarının çizimleri için teşekkür ederim. 
obsidyenin çekirdek parçası ve az sayıdaki yongalama artığına dayanılarak, malzemenin hammadde halinde yerleşime getirildiği ve yerleşim içerisinde yongalanarak aletler elde edildiği düşünülmektedir. Düzgün/paralel kenar ve sırt, sırt çizgisi ve homojen kalınlıkta, hafif içbükey olan dilgi bölümleri yongalamada baskı tekniğinin uygulandığını göstermektedir. Yine bu parçaların kenarlarında da kertik ve cilalanma şeklinde kullanım aşınımları gözlemlenmektedir.

\section{Çakmak Taşı}

Yerleşmede ele geçen çakmak taşları K. Demir tarafından, 1 adet yonga çekirdeği, 3 adet sırtlı bıçak (fig. 3a-c) 1 adet uç (fig. 3i) ve 3 adet yongalama artığ olarak belirlenmiştir. Sırtları dik düzeltilerle yapılmış sırtlı bıçaklardan ikisinin kullanım ağıları düzeltilerek keskinleştirilmiştir (fig. 3b-c). Çakmak taşı uç iki kenardan tek yüzeyli olarak düzeltilmiştir. Yontma taş buluntu yoğunluğunun azlığı, kesin yargılarda bulunulmasını engellemekle birlikte genel bir değerlendirmeyle yerleşmede hem çakmak taşı hem de obsidyenin alet yapımında kullanıldığını söylemek yanlış olmaz.
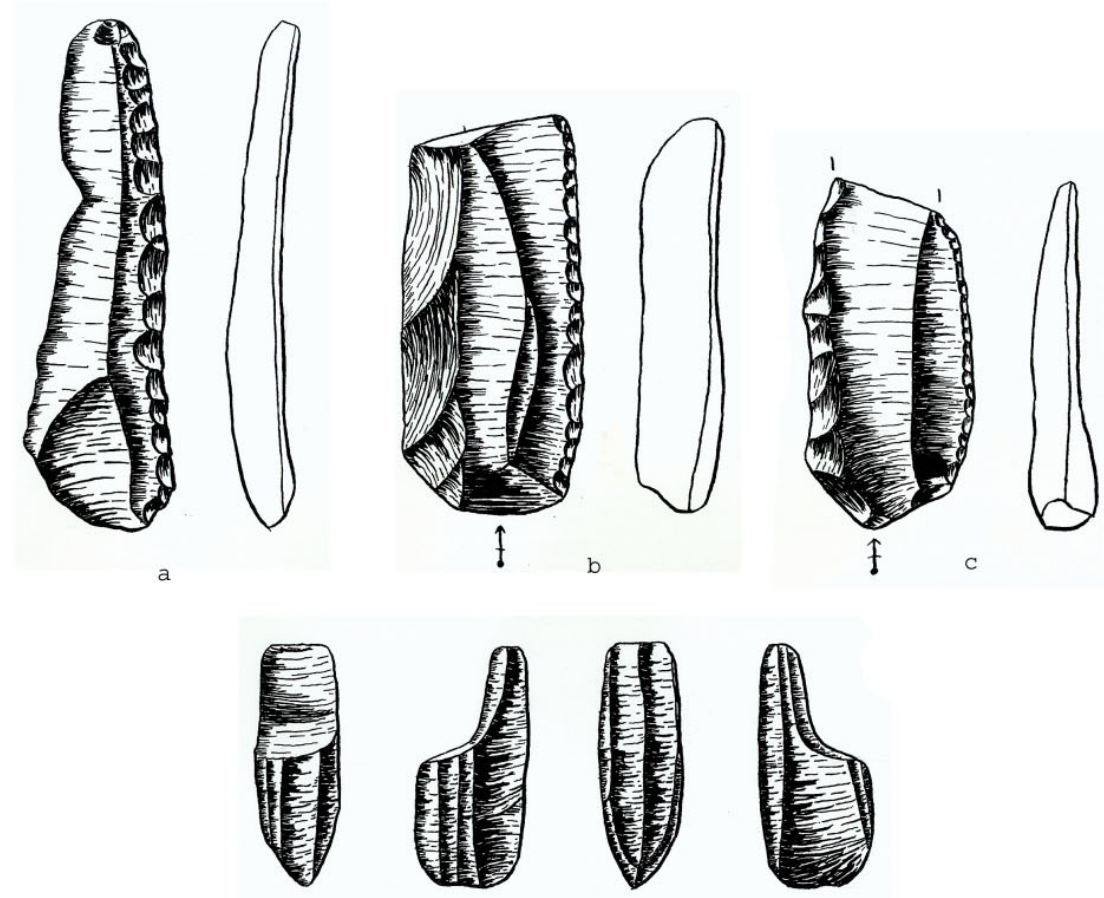

d
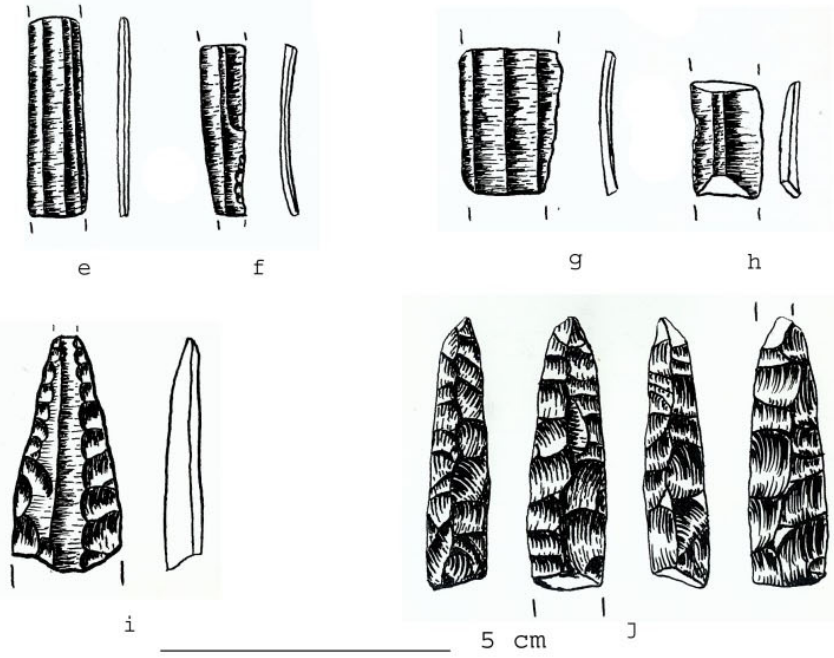

Figür 3: Akkise/Yahyalı Höyük'te ele geçen yontma taş alet parçaları 


\section{Öğütme Taşları}

Akkise/Yahyalı Höyük yerleşim yerinin neredeyse tamamının tarım arazisi olması ve arazinin gelişen teknolojik aletlerle daha derindeki kültür varlıklarını açığa çıkarmasından dolayı yerleşmenin değişik yerlerinde dağınık olarak kısmen kırılmış çok sayıda öğütme taşı bulunmuştur. Birçok Prehistorik yerleşmeden bildiğimiz öğütme taşlarının Akkise/Yahyalı yerleşmesinde ele geçen benzerlerinin de Neolitik ve/veya Kalkolitik Dönem'e tarihlenebileceği düşünülmektedir. Söz konusu öğütme taşları içinde bulunan birkaç kireçtaşı örnek dışında, kalanların tamamı, bazalt taş malzemeden yapılmıştır. Bunların bir kısmının havaneliyle birlikte bulunması, kullanım şekillerini göstermesi bakımından önemlidir (fig. 4). Öğütme taşları kendi içinde iki farklı grup altında değerlendirmiştir. Bunlardan ilki yuvarlak formda olanlardır. Bunların dışında kalan ikinci gurubu ise uzun yatay formda olanlar oluşturmaktadır. Bu örneklerden yatay formda olanların diğerlerine göre daha düz bir yüzeye sahip olduğu görülmüştür.
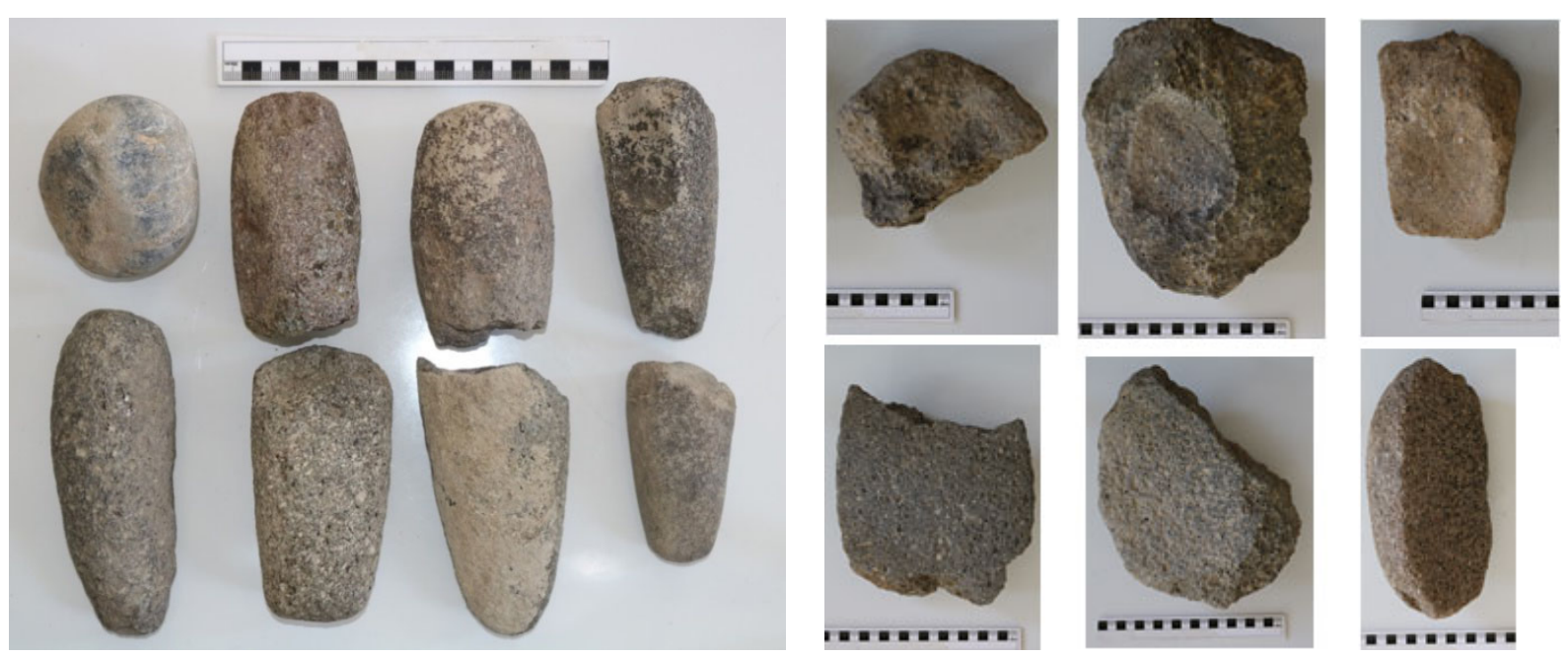

Figür 4: Akkise/Yahyalı Höyük'te tespit edilen bazı ögütme taşları ve havaneli örnekleri

\section{Pişmiş Toprak Eserler}

Akkise/Yahyalı Höyük'te yüzeyde ele geçen en yoğun buluntu gurubu birçok yerleşmede olduğu gibi çanak-çömlek parçalarından oluşmaktadır. Burada form veren ağız ve dip parçaları yanında çok sayıda gövde parçası da yüzeyden toplanmıştır (fig. 5-6). Bu yerleşmenin çanak çömleği, diğer birçok Seramikli Neolitik ve/veya Geç Neolitik Dönem ile Kalkolitik Dönem'e tarihlenen höyüklerden de bildiğimiz, genellikle koyu yüzlü olup, koyu kahverenginin farklı tonları yanında kırmızımsı kahve renkte açkılı mallarla karakterize olmaktadır. Günlük kullanıma yönelik üretilmiş oldukları tahmin edilen pişmiş toprak kapların katı veya sıvı gıdalar konulmak için kullanılmış olduğu düşünülmektedir. Yüzeyde kalın cidarlı, kaba diyebileceğimiz depolama kaplarına ait herhangi bir parça ele geçmemiştir. Gözle yapılan ilk incelemelere göre kaplar kendi içinde form ve yüzey özelliklerine göre farklı guruplara ayrılmaktadır. En genel haliyle değerlendirildiğinde, form olarak küresel gövdeli, dik yükselen, içe doğru hafif kapanan ă̆ızlı kaplar çömlekler olarak, hafif dışa çekik, açık ağızlı kaplar ise çanaklar olarak ayrılmıştır.

Burada değerlendirilen koyu yüzey renkli parçalardan, siyahımsı ve/veya grimsi renkli (Munsell 10YR-2/1,3/1), yüzeylerinden yoğun dumana ve ateşe maruz kaldığ1 anlaşılan çömleklerden bir kısmının pişirme kabı olarak kullanıldığı tahmin edilmektedir. Çömleklerin diğer bir kısmı ise kırmızı ve/veya kırmızımsı kahverengi (Munsell 2.5YR4/4,4/6) yüzey rengi bulunan parçalarla temsil edilirler (fig. 5). Parçaların büyük bir kısmının yüzeyinde, kap henüz kurumamış, nemli durumda iken perdahlandığını gösteren, 
yoğun perdah izleri gözle görülebilmektedir. Bazı örneklerin dış yüzeylerinde tahminen pişirmeden kaynaklı alacalanmalar söz konusudur. İncelenen parçalar arasında yüzeyinde boya veya kazıma herhangi bir bezeme, süsleme bulunan örnek tespit edilmemiştir. Bunlar üretim teknikleri açısından değerlendirildiklerinde, çömleklerin tamamının elde yapılıp şekillendirilmiş küresel gövdeli, basit ağız kenarlı12 bir forma sahip oldukları görülmüştür. Çömlek parçalarının cidar kalınlıkları 0.05-0.06 mm arasında değişmektedir. Bu parçaların yapılan ilk makroskopik incelemede kil hamur katkılarında organik katkı bulunmadığı, katkının daha çok ince taşcık ve/veya kum katkı yanında gözle görülebilecek boyutta kireç ve altın mika gibi mineral/inorganik maddelerden oluştuğu anlaşılmıştır. Çömleklerin genelde sıkı dokulu oldukları tespit edilmişken, bunlara göre daha küçük formda olan kapların gevşek dokulu oldukları ve daha kırılgan bir yapıya sahip oldukları anlaşılmaktadır. Ele geçen parçalardan anlaşıldığı kadarıyla çömlekler daha çok ip delikli tutamak $^{13}$ kulplardan oluşmakla birlikte bazı örneklerde tutamak kulplarda delik bulunmamaktadır. Çömleklerde kullanılan kulplar hilal, yarım ay veya üçgen diyebileceğimiz formdadır ${ }^{14}$. Bu tür tutamak formları daha çok Orta Anadolu'nun güneyinde bulunan Prehistorik Dönem yerleşmelerinden, Çatalhöyük Geç Neolitik ${ }^{15}$ ve Erken Kalkolitik ${ }^{16}$; Can Hasan Geç Neolitik ${ }^{17}$ Erken Kalkolitik18; Gökhöyük Bağları Höyük Geç Neolitik ve Kalkolitik19; Erbaba Geç Neolitik20; Yaka-Köşkhöyük Geç Neolitik Dönem'e21 tarihlenen tabakalardan bilinmektedir. Küçük formlu kaplarda kulpların hemen ağız kenarına, büyük formlu kaplarda ise daha çok kabın karına yakın kısmına tutturulduğu görülmüştür. Ele geçen kaide parçalarından kapların en azından belirli bir kısmının kaideye doğru daralan bir forma sahip oldukları anlaşılmaktadır. Kaideler kendi içinde halka kaideliler ve düz kaideliler olmak üzere iki farklı tipe ayrılmıştır.

İncelenen pişmiş toprak kap parçaları arasında ikinci gurubu oluşturan örnekler açık kaplar olarak değerlendirdiğimiz çanaklardır. Çanaklar yukarıda bahsettiğimiz ince cidarlı olan çömleklere oranla daha kalın cidarlı $(0.07-0.09 \mathrm{~mm})$ ve diğerlerine göre daha kaba özellikli parçalarla temsil edilmektedir. Bunların büyük çoğunluğunun yalın yüzeyli ve yüzeylerinin perdahlı olduğu anlaşılmaktadır. Bazı örnekler kahverengi ve kırmızının tonlarında (Munsell 2.5YR-4/4,4/6) astarlanmıştır. Bu nedenle çanak parçalarının iç ve diş renkleri birbirine daha yakındır. Form olarak dik yükselen, hafif dişa çekik, yayvan ă̆ızlı oldukları tahmin edilmektedir. Çanakların tutamaklarının formları da farklılık gösterir. Çanaklarda kullanılan tutamaklar genelde düz bir forma sahipken, çömleklerde kullanılan kulplar hilal, yarım ay veya kulak diyebileceğimiz formdadır. Çömleklerde olduğu gibi çanakların kulplarında da ip delikleri sık görülen bir özellik değildir. Özellikle daha küçük formlu oldukları düşünülen çanaklardaki tutmaklar kullanım yanında daha çok stilize edilmiş kulp izlenimi vermektedir. Burada ele alınan pişmiş toprak parçalardan bazılarının parlak yüzeyli olması yumuşak açkı uygulamasını işaret ederken, bazılarının yüzeylerinin ise mat görünümlü olması yapılan sert açkıdan kaynaklanmış olmalıdır. Bu çalışmada incelenen seramik parçalarının tamamı yüzeyden toplanıp temiz dolgulardan gelmediği için çömlekler arasındaki bu özelliklerin dönemsel mi yoksa formsal mi olduğu henüz anlaşılamamıştır. Akkise/Yahyalı yerleşmesinde ileride yapılacak kazılarda açığa çıkacak

\footnotetext{
12 Ökse 2012, 119.

13 Ökse 2012, 131.

14 Bu tür tutamakları Turan Efe "at nalı biçimli" olarak değerlendirmiştir (Özsait - Efe 2012, 33).

15 Mellaart 1961, 162, fig. 2; Özdöl 2006, fig. 27-140.

16 Gündüz 2013, fig. 12-14.

17 French 2005, 118-121, fig. 39-42. 7-4 tabaka.

18 Frech 2005, 171, fig. 92, 244, fig. 165. tabaka 2B.

19 Akgün 2019, kat. 330-333.

20 Özdöl 2006, fig. 147-188.

21 Özsait - Efe 2012, 36, lev. XIII1, fig. 33-37.
} 
stratigrafisi belirli steril tabakalar, bu konunun daha iyi anlaşılmasına büyük katkı sağlayacaktır.

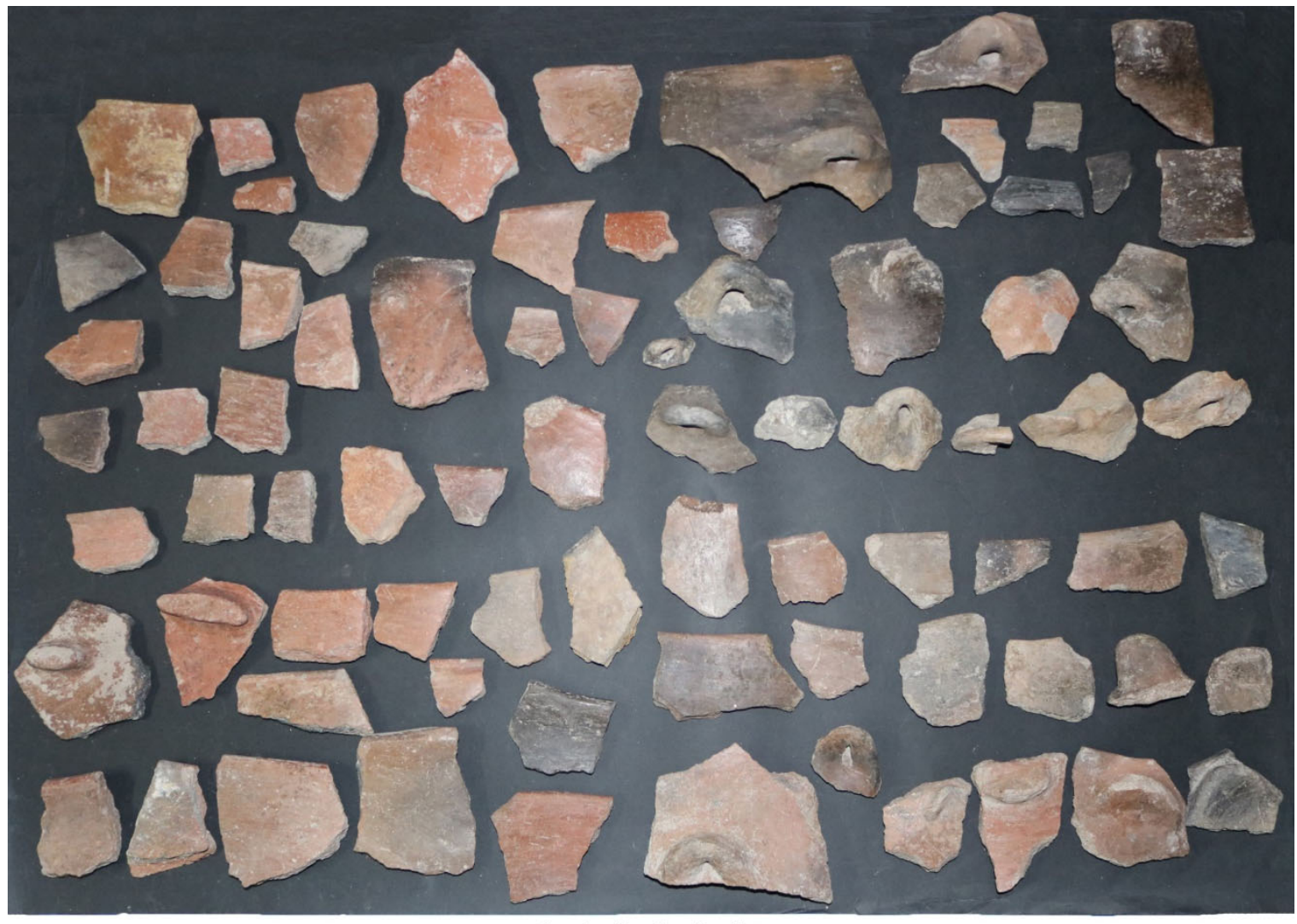

$$
{ }^{2}-2^{3}-{ }^{5 \mathrm{~cm}}
$$

Figür 5: Akkise/Yahyalı Höyük'te tespit edilen çanak-çömlek parçaları

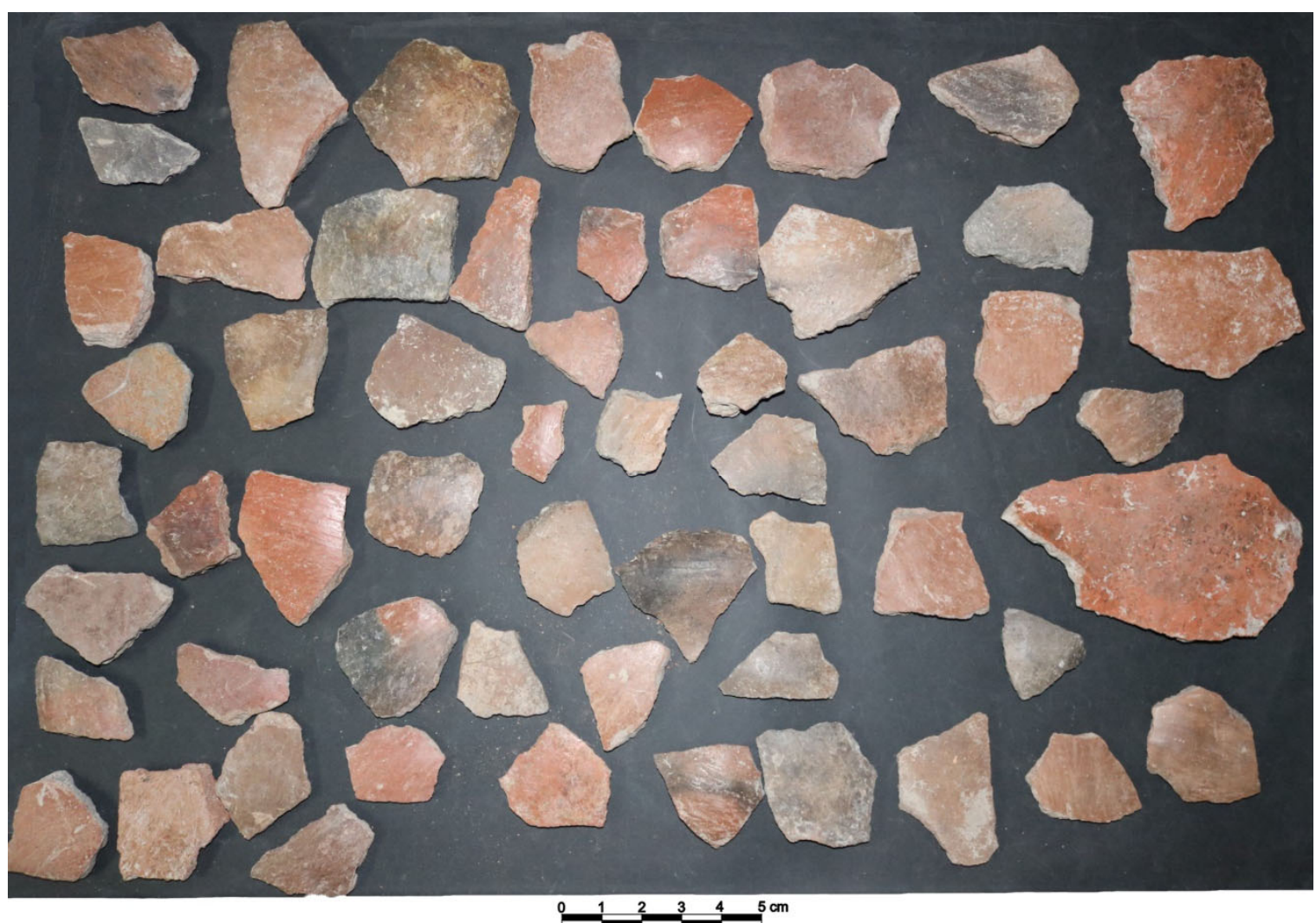

Figür 6: Akkise/Yahyalı Höyük'te tespit edilen amorf çanak-çömlek parçaları 


\section{Değerlendirme ve Sonuç}

Akkise/Yahyalı Höyük, Suğla Gölü'ne yakın bir yerde, tarıma elverişli verimli topraklar içinde bulunduğundan ve buna bağlı olarak yerleşmede yapılan yoğun tarım faaliyetlerinden dolayı tahribata maruz kalmaktadır. Tarım faaliyetleri sırasında yüzeye çıkan buluntular defineciler tarafından da fark edilmiş olacak ki bu alan ve çevresinde defineci çukurları açılarak, yerleşme tahrip edilmektedir. Akkise/Yahyalı Höyük'te yüzeyden toplanan buluntuların çoğunluğu Geç Neolitik, Erken Kalkolitik Dönem'e tarihlenebilecek pişmiş toprak kap parçalarından oluşmaktadır. Akkise/Yahyalı' da bunların dışında yine Prehistorik Dönem yerleşmelerinde bulunan yontma taş aletler ve ögütme taşları da mevcuttur. Açılan bir defineci çukuru ise yerleşmenin olası Prehistorik Dönem mimari geleneği hakkında bilgi vermektedir. Yerleşmede yapılan incelemelerde geç dönemlere tarihlenebilecek herhangi bir çanak-çömlek parçası ve/veya arkeolojik kalıntının olmaması, Akkise/Yahyalı'nın Prehistorik Dönem'de kullanıldıktan sonra herhangi bir tahribata/bozulmaya uğramadan günümüze ulaşmış olduğunu düşündürmektedir. Akkise/Yahyalı Höyük'te önümüzdeki yıllarda yapılacak arkeolojik kazılar, bölgede gerçekleştirilecek arkeolojik çalışmalara da yeni bir temel oluşturacaktır. Bunun yanı sıra kazılar sonucu açığa çıkarılacak yerleşme, bölgenin Neolitik Dönem kültürleri üzerine yeni verilerin elde edilmesine de olanak sağlayacaktır. Bu bağlamda Akkise/Yahyalı Höyük'ün Beyşehir-Suğla olarak adlandırılan koridorun Neolitikleşme süreci ve/veya bu dönemin başlangıç aşamaları hakkında da önemli bilgiler verecek bir potansiyelde olduğu düşünülmektedir. Akkise/Yahyalı yerleşim yerine yakın bir mesafede konumlanan Suberde ve Gökhüyük Bağları Höyük'te tespit edilen Neolitik Dönem buluntularının Akkise/Yahyalı Höyük'te de olması, bölgesel ilişkilerin anlaşılmasına katkı sağlayacaktır. Bunun yanında Akkise/Yahyalı' da ele geçen çanak çömlek parçalarının hem form hem yüzey özelliği olarak benzerlerinin Karaman Can Hasan Höyük'ten Isparta/Gelendost Yaka-Köşkhöyük'e kadar uzanan ve Orta Anadolu'nun güney kesimini kapsayan alan içinde görülüyor olması, Akkise/Yahyalı'nın bu bölge içindeki kültürel ve/veya ticari bir ağın parçası olabileceği ihtimalini de düşündürmektedir. Bir başka ihtimal ise birbirine çok yakın mesafede göl çevresinde kurulmuş olan Erbaba, Suberde, Gökhöyük Bağları Höyük ve Yahyalı gibi yerleşim yerleri arasında mikro düzeyde ticari ve/veya kültürel ilişkilerin varlığıdır. Suğla Gölü'nün çevresinde bulunan bu yerleşmelerde en kısa sürede kazılar başlatılıp, Anadolu'nun doğusu ile batısı arasında geçiş koridoru olabilecek olan bu bölgenin Neolitikleşme süreci ve yaşam biçimleri aydınlatılmalıdır. Böylece, Orta Anadolu'nun güneyi ile Göller Bölgesi arasındaki olası ilişkiler daha iyi anlaşılacaktır.

\section{Figürlerin Listesi}

Figür 1: Akkise/Yahyalı Höyük'ün konumu

Figür 2: Akkise/Yahyalı Höyük'te definecilerin kaçak kazıları sonrasında açığa çıkan taş duvarlı mimari yapı parçası

Figür 3: Akkise/Yahyalı Höyük'te ele geçen yontma taş alet parçaları

Figür 4: Akkise/Yahyalı Höyük'te tespit edilen bazı öğütme taşları ve havaneli örnekleri

Figür 5: Akkise/Yahyalı Höyük'te tespit edilen çanak-çömlek parçaları

Figür 6: Akkise/Yahyalı Höyük'te tespit edilen amorf çanak-çömlek parçaları 
Akgün 2019

Bordaz 1969

French 1998

French 2005

Gündüz 2013

Gündüz 2019

Kuzucuoğlu 2002

Mellaart 1954

Mellaart 1958

Mellaart 1961

Mellaart 1967

Munsell 2013

Ökse 2012

Özdöl 2006

Özsait - Efe 2012

\section{Bibliyografya}

E. Akgün, Seydişehir Gökhöyük Bă̆ları Höyüğ̈̈. Yayınlanmamış Yüksek Lisans Tezi, Selçuk Üniversitesi, Konya, 2019.

J. Bordaz, "The Suberde Excavations, South-Western Turkey: An Interim Report," Türk Arkeoloji Dergisi XVII/2 (1969), 43-71.

D. French, Canhasan Sites 1: Canhasan 1: Stratigraphy and Structures, London, 1998.

D. French, Canhasan Sites 2: Canhasan 1: The Pottery, London, 2005.

R. Gündüz, Die Dunkel Bemalte Keramik des 6. Jahrtausends v.Chr in der Ebene von Konya, Master Arbeit, Albert-Ludwigs Universität/ Archäologische Fakültät,- Ur - und Frühgeschichtliche Archäologie. Freiburg-Deutschland, 2013.

R. Gündüz, “Lykonia Bölgesinde Yeni Bir Yerleşme, Gökhöyük Bağları Höyüğ̈̈", Eds. H. Muşmal - E. Yüksel - M. A. Kapar. Karaman Araştırmalan I, Konya, 2019, 41-45.

C. Kuzucuoğlu, "The Environmental frame in Central Anatolia from the 9th to the 6th millenia cal BC", Eds. F. Gerard - L. Thissen. The Neolithic of Central Anatolia, CANeW International Table Ronde, İstanbul, 2002, 33-58.

J. Mellaart, "Preliminary Report on a Survey of Pre-classical Remains in Southern Turkey", Anatolian Studies 4 (1954), 175-240.

J. Mellaart, "Second Millennium Pottery from the Konya Plain Neighbourhood", Belleten XXII/87 (1958), 311-353.

J. Mellaart, "Early Cultures of the South Anatolian Plateau", Anatolian Studies 11 (1961), 159-184.

J. Mellaart, Çatal Hüyük, A Neolithic Town in Anatolia, New York, 1967.

Munsell Soil Color Charts. U.S. Gov. Print.

T. Ökse, Önasya Arkeolojisinde Çanak Çömlek. Teknik Özellikler, Biçimler, İstanbul, 2012.

S. Özdöl, Anadolu'da Erken Dönem Çanak Çömlek Kültürleri ve Çatal Höyük Örneği. Yayınlanmamış Doktora Tezi, Ege Üniversitesi, İzmir, 2006.

M. Özsait - T. Efe, "Yaka Köşk Höyükten Toplanan Neolitik ve Kalkolitik Dönem Çanak Çömleği", Arkeoloji Dergisi XVII (2012), 31-54. 